\title{
SERVİKAL OLGUNLAŞMA AMACI İLE UYGULANAN PROSTAGLANDİN E2 TEDAVISİNDE BAŞARIYI BELİRLEYEN FAKTÖRLERIN DEĞERLENDİRİLMESİ
}

\author{
EVALUATION OF THE FACTORS DETERMINING THE SUCCESS OF PROSTAGLANDIN \\ E2 TREATMENT FOR CERVICAL RIPENING
}

\author{
Hamdullah SÖZEN*, Gülşah ILHAN*, Doğan VATANSEVER**, Oya DEMİRCI***, \\ Aktuğ ERTEKİN***
}

\section{ÖZET}

Amaç: Doğum indüksiyonunun endike olduğu hastalarda, servikal olgunlaşma amacı ile uygulanan prostaglandin E2'nin başarısında etkili olabilecek faktörleri ortaya koymak.

Gereç ve Yöntem: Çalı̧̧maya fetal kardiyak aktivitesi (+), Bishop skoru 3'ün altında, baş prezentasyonu, reaktif nonstres testi (NST) olan ve aktif kontraksiyonu olmayan gebeler dahil edilmiştir. Servikal olgunlaştırma metodu olarak $10 \mathrm{mg}$ dinoproston yavaş salınımlı ovül kullanıldı. Servikal muayenede Bishop skoru 5'in üzerine çıkan hastalar tedavinin başarılı olduğu, 5 in altında kalanlar ise tedavinin başarısız olduğu grup olarak tanımlanmıştır. Her iki grup arasında yaş, gravida, parite, vajinal $\mathrm{pH}$, ilk kontraksiyonun ortaya çıkma zamanı, aktif kontraksiyonların ortaya çıkma zamanı, fetal ağırlık, fetal karın çevresi (AC) ve biparietal çap (BPD) karşılaştırıldı ve bu faktörlerin servikal olgunlaştırma metodu olarak uygulanan $10 \mathrm{mg}$ dinoproston yavaş salınımlı ovülün başarısı üzerine etkili olup olmadığı araştırıldı.

Bulgular: Maternal yaş, parite, son adet tarihi esas alınarak hesaplanan gebelik günü, fetal BPD, AC ölçümlerinin başarıyı belirlemede etkin olmadığı (p:0.54; p:0.06; p:0.11; p:0.123; p:0.127) ancak gebelik sayısı, servikal dilatasyon, efasman, vaginal $\mathrm{pH}$, ilk kontraksiyonun başlaması için geçen süre, etkin kontraksiyonların başlaması için geçen süre ve fetal ağırlı̆̆ın başarıyı belirlemede etkin olduğu gösterilmiştir (p:0.017; p:0.021; p:0.007; $<<0.01 ; \mathrm{p}<0.01 ; \mathrm{p}<0.01$; $\mathrm{p}: 0.046)$.

Sonuç: $10 \mathrm{mg}$ yavaş salınımlı dinoproston tedavisi öncesi obstetrik anamnez, fizik muayene ve ultrasonografik inceleme ile hastaların tedaviye muhtemel yanıtları anlaşılabilir. Gebelik sayısı yüksek olanlarda, servikal dilatasyon ve servikal efasmanı fazla olanlarda, ilk ve etkin kontraksiyonların erken çıkması halinde, vajen pH'sı yüksek kişilerde, 10 mg yavaş salınımlı dinoproston vajinal ovül ile elde edilen başarı artmaktadır.

Anahtar kelimeler: Doğum; indüksiyon; Prostaglandin E2; dinoporoston; serviks; olgunlaşma.

\begin{abstract}
Objective: To reveal the factors that may influence the success of prostaglandin E2 treatment applied for cervical ripening when induction of labor was indicated.

Materials and methods: Pregnant women with fetal cardiac activity, Bishop score of under 3, cephalic presentation, reactive nonstress test (NST) and without any active contractions were included. Controlled release ovules containing $10 \mathrm{mg}$ dinoprostone were used for cervical ripening. Bishop score of greater than 5 was defined as successful treatment group and lesser than 5 was identified as the group of failed treatment. Age, gravida, parity, vaginal $\mathrm{pH}$, time to the first contraction and time to the active contractions, fetal weight, fetal abdominal circumference (AC) and biparietal diameter (BPD) were compared between the two groups and assessed whether these factors influence the success of the dinoprostone treatment.
\end{abstract}

Date received/Dergiye geldiği tarih: 22.12.2015 - Date accepted/Dergiye kabul edildiği tarih: 30.07.2016

* Süleymaniye Kadın Doğum ve Çocuk Hastalıkları Eğitim ve Araştırma Hastanesi, Kadın Hastalıkları ve Doğum Kliniği

** Lütfi Kırdar Eğitim ve Araştırma Hastanesi, Kadın Hastalıkları ve Doğum Kliniği

*** Zeynep Kamil Kadın Doğum ve Çocuk Hastalıkları Eğitim ve Araştırma Hastanesi, Kadın Hastalıkları ve Doğum Kliniği, İstanbul, TÜRKIYYE

(Corresponding author/İletişim kurulacak yazar: gulsah.keskin.84@hotmail.com_) 


\section{Prostaglandın E2 ile servikal olgunlaşmaya etkili faktörler}

Results: While maternal age, parity, gestational day calculated on the basis of last menstrual period, fetal BPD, AC measurements were not significant in determining the success (p:0,54; p:0.06; p:0.11; p:0.123; p:0.127); gravida, cervical dilation and effacement, vaginal $\mathrm{pH}$, time to the first contraction and time to the active contractions, fetal weight were significant in determining the success of treatment (p:0.017; $\mathrm{p}: 0.021 ; \mathrm{p}: 0.007 ; \mathrm{p}<0.01 ; \mathrm{p}<0.01 ; \mathrm{p}<0.01$; p:0.046)

Conclusion: Prior to treatment with controlled release ovules containing $10 \mathrm{mg}$ dinoprostone, obstetric history, physical and ultrasonographic examination of patients may predict treatment responses. Patients with higher number of pregnancies, greater cervical dilation, effacement, higher vaginal $\mathrm{pH}$ and early appearance of first and effective contractions may increase treatment success.

Key Words: Labor; induction; prostaglandin E2; dinoporoston; cervix; ripening

\section{GíRIŞ}

Gebelik ortalama 280 gün süren, fetal ve maternal yapılarda bir dizi fizyolojik değişimin olduğu bir süreçtir. Doğum, fetusun dünyaya gelmesi için hem uterus, hem de serviksde çok sayıda değişikliği gerektirir. Doğumda servikal değişiklikler için önemli olan serviks komponentleri; glikozaminoglikanlar, dermatan sülfat, hyaluronik asit ve kollajendir $(1,2,3)$. Gebeliğin sonunda serviks, hyaluronik asit ve siv1 içeriğinin artışına, dermatan sülfat- kondroidin sülfat oranında azalma ve kollajenin azalmasına bağlı olarak şişer ve yumuşar, esneklik ve genişleme kabiliyeti kazanır (4).

Doğum eyleminin gerçekleşebilmesi için mutlaka uygun yapıda bir serviksin bulunması gerekmektedir. $\mathrm{Bu}$ amaçla servikal olgunlaştırma dediğimiz serviksin uygun pozisyon ve değişimi ile sonuçlanan işlemlere gereksinim bulunmaktadır. Doğum indüksiyonunun gerektiği intrauterin gelişme kısıtlılı̆̆ı, preeklampsi, erken membran rüptürü, korioamnionit, mort fetus, anneye bağlı doğumun indüklenmesini gerektiren kronik hastalıklar, postterm gebelik gibi durumlarda, gebelerin birçoğunda serviks uygun değildir. Dinoproston (11,15s-dihidroksi-9-oksoprosta-5z,13Edien-l-oik asit) servikal olgunlaştırmada en s1k kullanılan ve düzenli salım, dokulardan hızlı eliminasyon ile yan etki potansiyelinin az olduğu prostaglandin içeren bir preparattır $(5,6)$. Servikal olgunlaşmayı kollajenaz ve elastaz aktivitesini arttırarak, servikal düz kaslarda gevşemeye sebep olarak ve fundal myometriumda kontraksiyonlar oluşturarak gerçekleştirir. Ayrıca doğumu başlatacak koordineli uterin kontraksiyonlar için gerekli olan hücreler arası gap-junction formasyonunu kolaylaştırır. Neticede uterus oksitosine karşı daha duyarlı hale gelir $(7,8)$.

Gebede serviksinin çeşitli değişkenler kullanılarak skorlanması ve tanımlanması hangi gebelerin güvenli ve başarılı bir şekilde indüksiyon alabileceğini ve doğum süresinin tahmini için kullanılmaktadır (9). Bishop skoru günümüzde bu amaçla en sık kullanılan skorlama sistemidir $(9,10)$. Burnett gibi modifiye skorlama sistemleri, O’Leary ve Ferrell ya da Crane ve arkadaşları' nın yapmış olduğu gibi ultrasonografik skorlama sistemi oluşturulmuş ancak Bishop skorlamaya göre herhangi bir üstünlükleri olmadığ1 görülmüştür $(11,13)$. Hartfield ve arkadaşları tarafindan tamamlanmış olup transvajinal olarak servikal uzunluğun ölçüldüğü ve indüksiyon başarısını öngörmeyi amaçlayan meta-analizde çalışmanın heterojenitesi sebebiyle tatmin edici bir sonuç alınamamıştır (14).

Biz de çalışmamızda doğum indüksiyonunun endike olduğu hastalarda; servikal olgunlaşma amacı ile uygulanan prostaglandin E2' nin başarısını Bishop skoru ile değerlendirip, bu başarıda etkili olabilecek faktörleri ortaya koymayı amaçladık.

\section{GEREÇ VE YÖNTEM}

Çalışmamız Haziran 2010 ve Aralık 2010 tarihleri arasında Zeynep Kamil Kadın ve Çocuk Hastalıkları Eğitim ve Araştırma Hastanesi, Kadın Hastalıkları ve Doğum Kliniği’nde yapıldı. Çalışma öncesinde Zeynep Kamil Kadın ve Çocuk Hastalıkları Eğitim ve Araştırma Hastanesi Etik Kurulundan onay alınmıştır. Bu çalışmaya baş prezentasyonunda, fetal kardiyak aktivitesi (+) fetus taşıyan, Bishop skoru 3' ün altında, reaktif nonstres testi (NST) olan ve aktif kontraksiyonu olmayan gebeler dahil edilmiştir.

$\mathrm{Bu}$ çalışmada; doğum eylemi başlayan, membran rüptürü olan, oksitosik ilaç kullanan, majör uterin veya servikal operasyon geçiren, zor doğum hikayesi olan, grand multipar, uterin kontraksiyonları olan, sefalopelvik uygunsuzluk tanısı alan, daha önce sezaryen doğum hikayesi olan, dinoproston kullanımına aşırı duyarlılığı olan gebeler, çoğul gebelikler, fetal malprezentasyonlar, fetal anomaliler, plasenta previa, koryoamniyonit tanısı alan vakalar çalışma dışı bırakılmıştır.

Çalışma grubunu belirlemeden hemen önce hastanın fetal ultrasonografisi ve jinekolojik muayenesi aynı kişi tarafından yapıldı. Tansiyon, nabız ve ateş ölçümü yapıldı. Hastanın obstetrik anamnezi alındı. Fetal kalp hızları ve uterin kontraksiyonları NST ile görüntülendi. Dinoproston uygulanması planlanan hastalara tedavi hakkında bilgi verildi onamları alındı. Uygun kriterleri taşıyan hastalara $10 \mathrm{mg}$ dinoproston yavaş salınımlı vajinal ovul (Propess ${ }^{\circledR}$ ovül) litotomi pozisyonunda arka fornikse uygulandı. Endojen prostaglandin salınımı engellemek için servikal manipulasyondan kaçınıldı. Herhangi bir hastaya membran siyırma ve servikal dilatasyon uygulanmadi. Tedavi uygulanmasından hemen önce her hastanın vajinal $\mathrm{pH}$ değeri ölçüldü ve 
kaydedildi. Hastalara dinoproston uygulandıktan sonra yakın NST takibine başlandı. NST de ilk çıkan kontraksiyon zamanı ve etkin kontraksiyonların oluştuğu (20 dakikada 3 kontraksiyonun) zamanlar kaydedildi. Hastaların tedavi sonrası 4, 6, 8 ve 12 . saatlerde Bishop skorlamaları tekrarlandı ve yine aynı şekilde servikal manipulasyondan kaçınıldı. Kardiyotokografik monitörizasyonda patolojik fetal kalp hızı paternleri Kubli ve ark. nın tanımladığı şekilde belirlendi (15). Bu sınıflama fetal taşikardi, bradikardi, geç deselerasyon, orta veya ciddi variable deselerasyonları içeriyordu. Uterin patolojik hiperaktivite Amerikan Obstetri ve Jinekoloji Derneğinin tanımladığı şekilde belirlendi. Taşisistoli, 10 dakikalık sürede en az 6 kontraksiyonun olması, hipertonus tek kontraksiyon süresinin 2 dakikadan fazla olması, hiperstimülasyon ise taşisistoli ve hipertonusun anormal fetal kalp hızı ile birlikte olması olarak tanımlandi.

Oniki saatlik süreç boyunca fetal distress sebebi ile sezaryene alınan hastalar, uterin hiperaktivite sebebi ile $10 \mathrm{mg}$ dinoproston ovülün çekilmek zorunda kalındığ1 hastalar çalışma dışı bırakıldılar. Oniki saatlik tedavi sonucunda yapılan servikal muayenede Bishop skoru 5 in üzerine çıkan hastalar propess tedavisinin başarılı olduğu grup, Bishop skoru 5'in altında kalan grup ise tedavinin başarısız olduğu grup olarak tanımlanmıştır. Her iki grup arasında yaş, gravida, parite, vajinal $\mathrm{pH}$, ilk kontraksiyonun ortaya çıkma zamanı, aktif kontraksiyonların ortaya çıkma zamanı, fetal ağırlık, tedavi öncesi fetal karın çevresi ve fetal baş çevresinin karşılaştırılması ile bu faktörlerin servikal olgunlaştırma metodu olarak uygulanan $10 \mathrm{mg}$ dinoproston yavaş salınımlı ovülün başarısı üzerine etkili olup olmadığı araștırıldı.

$\mathrm{Bu}$ çalışmada istatistiksel analizler NCSS 2007 paket programı ile yapılmıştır. Gruplar arası istatistikler için uygun olduğu yerde Mann-Whitney U Testi, ki kare testleri kullanılmıştır. İstatistiksel olarak anlamlılık $p<0.05$ olarak tanımlanmıştır.

\section{BULGULAR}

Çalışmaya kriterlerimizi karşılayan 90 gebe dahil edildi. $\mathrm{Bu}$ gebelerde $10 \mathrm{mg}$ yavaş salınımlı dinoproston tedavisinin başarılı olduğu grup (n:52) ile başarısız olduğu gruptaki (n:38) yaş dağılımı ve gebelik sayısının dinoproston tedavisine olan etkisi araştırılmış ve sonuçlar Tablo 1'de gösterilmiştir. Tedavinin başarılı olduğu grup ile tedavinin başarısız olduğu grup arasında ortalama yaş değerleri arasında istatistiksel olarak anlamlı bir farklılık bulunamamış olup ( $p: 0.54)$, maternal yaşın dinoproston tedavisinde başarıy öngörmede etkisiz olduğu görülmüştür. Her iki grup arasında gebelik sayıs1 farkının istatistiksel olarak anlamlı olduğu ( $p: 0.017)$, gebelik sayısı artışının dinoproston başarısını artırdığı izlenmiştir.

Tablo 1: Tedavinin başarılı ve başarısız olduğu gruplara göre yaş ve gebelik sayısı(Gravida) dağılımı.

$\begin{array}{lccccc} & \text { Ortalama yaş } & \text { G1 } & \text { G2 } & \text { G3 } & \text { G4 } \\ \text { Başarısız grup (n:38) } & 27,37(18-36) & 30(\% 78.9) & 2(\% 5.3) & 6(\% 15.8) & 0 \\ \text { Başarılı grup(n:52) } & 26,69(18-36) & 28(\% 53.8) & 8(\% 15.4) & 14(\% 26.9) & 2(\% 3,8) \\ \text { p } & 0,54 & \mathbf{0 , 0 1 7} & & & \\ \text { G: Gravida, } & & & & & \\ \text { n: Hasta sayıs1 } & & & & \end{array}$

Tablo 2: Doğum sayısı(Parite) ve gebelik gün sayısının tedaviye cevaba etkisi

$\begin{array}{lccll} & \text { P0 } & \text { P1 } & \text { P2 } & \text { Ortalama gebelik günü } \\ \text { Başarısız grup(n:38) } & 30(\% 79) & 6(\% 15.7) & 2(\% 5,3) & 284,05 \pm 9,26(259-299) \\ \text { Başarılı grup(n:52) } & 32(\% 61.5) & 8(\% 15.3) & 12(\% 22,5) & 277,69 \pm 17,534(223-301) \\ \text { p } & 0,06 & & & 0,11 \\ \begin{array}{l}\text { P: Parite, } \\ \text { n: Hasta sayıs1 }\end{array} & & & & \end{array}$

Parite ve son adet tarihine göre hesaplanan gebelik gününün dinoproston başarısına etkisi incelenmiş olup sonuçlar tablo 2'de gösterilmiştir. Her iki grup arasında parite sayısında anlamlı derecede bir fark olmadı $\breve{g}_{1}$ görülmüştür (p:0.06). Ayrıca son adet tarihi esas alınarak hesaplanan gebelik gününün dinoproston başarısını belirlemede etkin olmadığı görülmüştür (p:0.11).
Hastaların servikal dilatasyonu tedavi başlamadan hemen önce ölçülmüş ve tedavi başarısını öngörmede etkinliği araştırılmıştır (Tablo 3). Tedavinin başarılı olduğu grupta istatistiksel olarak anlamlı bir şekilde, servikal dilatasyonu 1 ve $2 \mathrm{~cm}$ olan hasta sayıs tedavinin başarısız olduğu gruba göre fazla idi $(p: 0.021)$. 
Prostaglandın E2 ile servikal olgunlaşmaya etkili faktörler

Tablo 3: Servikal dilatasyon, servikal efasman ve vajinal ph değerlerinin tedaviye etkisi.

\begin{tabular}{|llllll} 
& $\begin{array}{l}\text { Dilatasyon } \\
\text { yok }\end{array}$ & $\begin{array}{l}\mathbf{1 c m} \\
\text { dilatasyon }\end{array}$ & $\begin{array}{l}\mathbf{2} \mathbf{c m} \\
\text { dilatasyon }\end{array}$ & $\begin{array}{l}\text { Ortalama servikal } \\
\text { efasman \% }\end{array}$ & Ortalama Ph \\
\hline Başarısız grup & $22(\% 57,80)$ & $16(\% 42,10)$ & 0 & $\% 22,50$ & $4,184 \pm 0,294(4,0-7,0)$ \\
Başarılı grup & $18(\% 34,61)$ & $28(\% 53,84)$ & $6(\% 11,53)$ & $\% 11,05$ & $5,413 \pm 0,932(4,0-8,0)$ \\
p & $\mathbf{0 , 0 2 1}$ & & & $\mathbf{0 , 0 0 7}$ & $<\mathbf{0 , 0 1}$
\end{tabular}

Bishop muayenesi esnasında bakılmış olan servikal efasman miktarı da yine tedaviye başarılı olarak cevap veren ve vermeyen gruplarda değerlendirilmiş olup, her iki grup arasında istatistiksel olarak anlamlı derecede fark izlenmiştir ( $p: 0.007)$.

Hastalara yavaş salınımlı dinoproston tedavisi başlamadan önce elde edilen $\mathrm{pH}$ değerleri tedaviye başarı ile cevap veren grup ile başarısız şekilde cevap veren gruplar arasında karşılaştırıldı ve iki grubun $\mathrm{Ph}$ değeri arasında istatistiksel olarak anlamlı fark bulunmuştur $(p<0.01)$.
Dinoproston uygulamasından sonra ilk kontraksiyon başlaması ile aktif kontraksiyonların (20 dakikalık NST de 3 kontraksiyon) başlamasına kadar geçen süreler incelendiğinde (Tablo 4) tedaviye başarı ile cevap veren grupta ilk kontraksiyon başlama süresinin ve etkin kontraksiyon başlama süresinin daha az olduğu ve sonuçların istatistiksel olarak anlamlı olduğu görülmüştür $(p<0.01-p<0.01)$.

Tablo 4: Kontraksiyon zamanları, fetal ağırlıkların tedaviye etkisi

\begin{tabular}{llll} 
& $\begin{array}{l}\text { Kontraksiyon } \\
\text { başlaması için geçen } \\
\text { süre (dakika) }\end{array}$ & $\begin{array}{l}\text { Aktif kontraksiyon } \\
\text { başlaması için geçen süre } \\
\text { (dakika) }\end{array}$ & $\begin{array}{l}\text { Ortalama fetal } \\
\text { Ağırlık (gr) }\end{array}$ \\
\hline Başarısız grup & $261,18 \pm 79,14$ & $400,00 \pm 88,15$ & $3336 \pm 19,380(1040-4120)$ \\
Başarılı grup & $134,62 \pm 71,23$ & $214,42 \pm 106,53$ & $3197 \pm 29,266(1400-3950)$ \\
p & $<\mathbf{0 , 0 1}$ & $<\mathbf{0 , 0 1}$ & $\mathbf{0 , 0 4 6}$
\end{tabular}

Tablo 5: Ultrasonografi parametrelerinin(BPDAC) tedaviye etkisi.

$\begin{array}{lcc} & \begin{array}{l}\text { Ortalama } \\ \text { BPD ölçümü }\end{array} & \begin{array}{l}\text { Ortalama } \\ \text { AC ölçümü }\end{array} \\ \text { Başarısız grup } & 91,84 \pm 5.20 & 339,21 \pm 29,26 \\ \text { Başarılı grup } & 90,81 \pm 4,71 & 336,35 \pm 19,380 \\ \text { p } & 0,123 & 0,127\end{array}$

BPD: Biparietal diameter,

AC: Abdominal circumference

Ortalama fetal ağırlığın tedavi başarısına etkinliği incelendiğinde gruplar arası istatistiksel olarak anlamlı farklılık bulunmuştur ( $p: 0.046)$.

Hastaların dinoproston uygulamasına başlamadan önce yapılan ultrasonografisi değerlendirilmiştir. Buradaki fetal BPD ve AC ölçümlerinin tedavi başarısındaki etkinliği araştırılmıştır (Tablo5). Her iki parametre içinde tedavinin başarılı olduğu grupta değerler daha düşük bulunmasına rağmen yapılan istatistiksel incelemede anlamlı bir fark izlenememiştir ( $p$ :0.123p:0.127).

\section{TARTIŞMA}

Doğum eyleminin olmazsa olmazı serviksin belirli bir olgunluğa ulaşıp açılmaya başladığı, aşamadır. PGE2' nin fetal ve maternal yan etkilerinin az olması nedeniyle 10 mg dinoproston bütün dünyada bu amaçla daha fazla kullanılmaya başlamıştır (16). Prospektif olarak dizayn edilmiş çalışmamızda hastanemizde servikal olgunlaşma amacı ile uygulanmış olan $10 \mathrm{mg}$ yavaş salınımlı dinoproston tedavisini inceledik. Çalışma sonucunda gravida sayısının, vajinal $\mathrm{pH}$ değerinin, ilk kontraksiyonun ve etkin kontraksiyonun ortaya çıkma zamanının, fetal ağırlığın, servikal açıklık ve servikal efasmanın başarıyı belirleme hususunda etkili olduğunu bulduk.

Literatürde maternal yaş ile ilgili farklı sonuçlar bulunmaktadır. İlerlemiş maternal yaşın tedavinin etkinliğini düşürdüğü ve tedavi başarısızlığına yol açtığını ifade eden çalışmaların yanında $(17,19)$, ileri maternal yaşın dinoproston tedavisine cevapta herhangi 
bir etkisinin olmadığını gösteren çalışmalar da bulunmaktadır (20-22). Bizim çalışmamızda da maternal yaşın dinoproston tedavisinde başarıyı belirlemede etkin bir rolü olmadığ 1 gösterilmiştir (p:051).

Dinoproston tedavi başarısı ve gravida ilișkisini literatürde incelediğimizde Cochrane Library Review in (2003)teki yayınında gravidanın dinoproston başarısını belirlemede herhangi bir etkisi olmadığı gösterilmiştir (22). Bizim çalışmamızda ise gebelik sayısının 2 veya üzerinde olmasının $10 \mathrm{mg}$ yavaş salınımlı dinoproston tedavisinde başarı şansını artıran, gebelik sayısının 1 olması ise tedavi başarısını azaltan bir faktör olarak tanımlanabilinir.

Obstetrik özgeçmiş üzerine araştırmalarda daha fazla parite anamnezi incelenmiş olup eğilim daha fazla nulliparitenin servikal olgunlaştırma üzerine negatif etkisi olduğu yönünde yoğunlaşmıştır. Calder ve MacKenzie nin yaptığı derlemede nulliparitenin dinoproston tedavisinde başarıyı azaltan bir faktör olduğu savunulmuştur (23). Literatürde parite artışının dinoproston tedavisine başarı ile cevap vermede etkili olduğunu gösteren çok sayıda çalışma bulunmaktadır $(17,23,26)$. Cochrane Library Review'in 2003'deki yayınında paritenin ilaç etkinliği üzerine istatistiksel olarak anlamlı oranda etkisi olduğu belirtilmiştir. Biz de çalışmamızda 2 ve üstü parite değerlerinde dinoproston başarısının artmış olduğunu göstermemize rağmen 2' nin altındaki parite değerlerinde dinoproston başarısının azaldığını ancak bunun istatistiksel olarak anlamlı değere çok yakın olmasına rağmen istatistiksel olarak anlamlı bulunmamıştır ( $p$ :0.065).

Gestasyonel yaşın PGE2 başarısı üzerine olan etkisi yine çokça çalışılmış olup, prematurite ile beraber dinoproston başarısızlığının arttığı $(18,21,24)$, buna karşı bir tez olarak da ileri gestasyonel yaşta prostaglandin reseptör seviyesindeki azalmaya bağl1 olarak prostaglandin tedavisine cevabın azaldığını bildirilmiştir (27). Bizim sonucumuz ise bu iki görüşten farklı olarak gestasyonel yaşın tedaviye cevabı belirlemede herhangi bir etkisi olmadığ 1 yönündedir.

Çalışmamızda Bishop parametrelerinden servikal dilatasyon ve servikal efasman da değerlendirildiğinde $1 \mathrm{~cm}$ ve üstü servikal açıklıkta dinoproston başarısının $\operatorname{arttığ} 1,1 \mathrm{~cm}$ ve altındaki değerlerde ise dinoproston başarısının azaldığı görüldü. Bishop parametrelerinden servikal dilatasyonun doğum indüksiyonuna başarıda en önemli parametre olduğu daha önce birçok otör tarafından ifade edilmiş olmasına rağmen (28-33), dinoproston tedavisindeki başarıya olan etkisi fazla araştırılmamıştır. Bizim sonuçlarımızla korele bir şekilde literatürde servikal açıklığın $1 \mathrm{~cm}$ altında olmasının $10 \mathrm{mg}$ yavaş salınımlı dinoproston başarısını olumsuz yönde etkilediğini belirtilmiştir (19).

Servikal efasmanda ise çalışmamızda açıklık yüzdesinin tedaviye karşı başarıyı belirleyen temel parametrelerden biri olduğu artan yüzdelerle beraber dinoprostona karş1 başarının arttığı gösterilmiştir. Literatürde $\% 50$ altındaki efasman değerlerinde başarının oldukça azaldığı belirtilmiştir (19).

Dinoproston tedavisindeki etkin $\mathrm{pH}$ değerinin saptanması üzerine de birçok araştırma yapılmıştır.
Ramsey ve arkadaşları tarafından yapılan 2002'deki çalışmada artmış $\mathrm{pH}$ değerinin dinoproston tedavisinin hastaların eylem sırasında aktif faza geçme hızını, doğum süresini ve servikal açıklığı arttırma süresini anlamlı derecede arttırdığı iddia edilmiştir (34). Ramsey ve arkadaşları nın 2003'deki bir başka çalışmasında pH değişikliklerinin hastaların doğum zamanına, servikal dilatasyon artma hızına, Bishop skorunu değiştirme hızına herhangi bir etkisi olmadığı gösterilmiştir (35). Bizim çalışmamızda vajinal $\mathrm{pH}$ değerini tedaviye olumlu cevap veren grupta olumsuz cevap veren gruba nispeten anlamlı derecede yüksek bulduk.

Çalışmamızda dinoproston tedavisinin başarısı üzerine fetal ultrasonografik değerlendirme ile ilgili parametrelerin (BPD, AC) etkisini araștırdık. Tedaviye olumlu cevap veren grupta ortalama AC ve BPD' nin tedaviye başarı ile yanıt veren grupta daha az olduğu görülmüştür. Fakat her iki değer için de fark, istatistiksel olarak anlamlı çıkmamıştır ( $p: 0.12$ ve $p: 0.12)$. Bu hususta literatürde herhangi bir yayın bulunmamaktadır.

Çalışmaya başlamadan önceki literatür incelememizde dinoproston uygulanan hastaların ne kadar süre sonra uterin kontraksiyonlarının başladığı ile ilgili bir çalışma yapılmadığını gördük. Bizim çalışmamızda her iki grup arasındaki fark istatistiksel olarak anlamlı bulunmuştur. $\mathrm{Bu}$ sonuçlar eşliğinde dinoproston tedavisine uterin kontraksiyon olarak erken cevap veren hastalarda, tedavi başarısının daha iyi olduğundan bahsetmek doğru olacaktır.

Fetal ağırlıkların ortalamaları her iki grup içinde karşılaştırılmış ve tedaviye başarı ile cevap veren grupta fetal ağırlık ortalaması 3197 gramken, tedaviye olumsuz cevap veren grupta fetal ağırlı ortalaması 3336 gram bulunmuştur. Aradaki fark istatistiksel olarak anlamlı bulunmuştur. Literatürde fetal ağırlık olarak 2500 ve altındaki değerlerde dinoproston tedavisinin başarısız olduğunu tanımlanmıştır (19).

\section{SONUÇ}

10 mg yavaş salınımlı Dinoproston tedavisi öncesi hastaların fizik muayene, ultrasonografik inceleme ve obstetrik anamnez ile hastaların tedaviye muhtemel yanıtları anlaşılabilir. Gebelik sayısı yüksek olanlarda, servikal açıklığı ve servikal efasmanı fazla olanlarda, ilk ve etkin kontraksiyonların erken çıkması halinde, vajen pH'sı yüksek kişilerde, $10 \mathrm{mg}$ yavaş salınımlı Dinoproston vajinal ovüle karşı elde edilen başarı artmaktadır.

\section{KAYNAKLAR}

1. Leppert PC, Cerreta JM, Mandl I. Orientation of elastic fibers in the human cervix. Am J Obstet Gynecol 1986;155:219-24.

2. Uldbjerg $\mathrm{N}$, Ilmsten U, Ekman G. Clin Obs. Gynecol 1986;26:14-26.

3. Minamoto T. Immunohistochemical studies on collagen types in the uterine cervix in pregnant and nonpregnant states. Am J Obstet Gynecol 1987;156:138-44.

4. Huszar G, Walsh M. A cellular view of uterine function, myometrium and cervix in Prostaglandins 
for cervical ripening and/or induction of labor. Edited C.Eganter-P.Husslein, Fac. Un. Ges.m.b Austria 1988;9-32.

5. Owen J. A randomized, double-blind trial of prostaglandin E2 gel for cervical ripening and metaanalysis. Am J Obstet Gynecol 1991;165: 991-6.

6. Brindley BA, Sokol RJ. Induction and augmentation of labor: basis and methods for current practice. Obstet Gynecol Surv 1988; 43:730-43.

7. Hamid Hadi. Cervical Ripenning and Labor Inductıon: Clinical Guidelines. Clinical Obstetrics And Gynecology 2000;43: 524-36.

8. Leszczynska - Gorzelak B, Laskowska M, Oleszczuk J. Comparative analysis of the effectiveness of misoprostol and prostaglandin E2 in the preinduction and induction of labor. Med Sci Monit 2001;7:1023-8.

9. Leppert PC. Cervikal softening, effacement and dilatation: A complex biocemical cascade. Journal of Maternal and Fetal Medicine 1992;213-23.

10. Edwards RK, Richards DS. Preinduction Cervial Assessment. Clinical Obstetrics And Gynecology 2000;43:433-9.

11. Burnett JE. Preinduction scoring: an objective approach to induction of labor. Obstet Gynecol 1966;28:479-83.

12. Fetal macrosomia. ACOG Technical Bulletin Number 159--September 1991. Int J Gynaecol Obstet 1992;39:341-5.

13. Crane JM, Delaney T, Hutchens D. Transvaginal ultrasonography in the prediction of preterm birth after treatment for cervical intraepithelial neoplasia. Obstet Gynecol 2006;107:37-44.

14. Hatfield AS, Sanchez-Ramos L, Kaunitz AM. Sonographic cervical assessment to predict the success of labor induction: a systematic review with metaanalysis. Am J Obstet Gynecol 2007;197:18692.

15. Kubli F, Boos R, Rüttgers H, Hagens C von, Vanselow H. Antepartum FHR-Monitoring. In R. W. Beard and S. Campbell (Eds.), Current status of FHR-Monitoring and Ultrasound in Obstetrics, Royal College of Obstetricians and Gynaecologists, London, 1978:(671-2).

16. Ayaz, A, Shaukat S, Farooq MU, Mehmood K, Ahmad I, Ali Bahoo ML. Induction of labor: a comparative study of intravaginal misoprostol and dinoprostone. Taiwan J Obstet Gynecol 2010;49:151-5.

17. Bortolus R. Determinants of response to intracervical prostaglandin E2 for cervical ripening. Gruppo di Studio sull'Induzione del Travaglio di Parto. Eur J Obstet Gynecol Reprod Biol 1999;87:137-41.

18. Daskalakis G, Thomakos N, Hatziioannou L, Mesogitis S, Papantoniou N, Antsaklis A. Sonographic cervical length measurement before labor induction in term nulliparouswomen. Fetal Diagn Ther 2006;21:34-38.

19. Melamed, N, Ben-Haroush A, Kremer S, Hod M, Yogev Y. Failure of cervical ripening with
prostaglandin-E2 can it be predicted? J Matern Fetal Neonatal Med 2010;23:536-40.

20. Caliskan E, Dilbaz S, Gelisen O, Dilbaz B, Ozturk $\mathrm{N}$, Haberal A. Unsucessful labour induction in women with unfavourable cervical scores: predictors and management. Aust N Z J Obstet Gynaecol 2004;44:562-7.

21. Karaiskakis PT, Rayburn WF, Smith CV, Woods RE. Failed induction of labor despite sequential prostaglandin E2 therapy. Am J Perinatol 1991;8:128-30.

22. Kelly AJ, Kavanagh J, Thomas J. Vaginal Prostaglandin (PGE2 and PGEF2a) for Induction of Labor at Term. Cochrane Database Syst Rev, 4;2003.

23. Calder A, MacKenzie I. Review of Propess-A controlled release Dinoproston (prostaglandin E2) Pessary. J. Obstet. Gynecol 1997;63-67.

24. Melamed N, Yogev Y, Hadar E, Hod M, BenHaroush A. Preinduction cervical ripening with prostaglandin E2 at preterm. Acta Obstet Gynecol Scand 2008;87:63-7.

25. Yogev Y, Ben-Haroush A, Gilboa Y, Chen R, Kaplan B, Hod M. Induction of labor with vaginal prostaglandin E2. J Matern Fetal Neonatal Med 2003;14:30-4.

26. Prysak M, Castronova FC. Elective induction versus spontaneous labor: a case-control analysis of safety and efficacy. Obstet Gynecol 1998;92:47-52.

27. Grigsby PL, Sooranna SR, Adu-Amankwa B, Pitzer B, Brockman DE, Johnson MR, et al. Regional expression of prostaglandin E2 and F2 alpha receptors in human myometrium, amnion, and choriodecidua with advancing gestation and labor. Biol Reprod 2006;75:297-305.

28. Friedman EA, Sachtleben MR. Determinant role of initial cervical dilatation on the course of labor. Am J Obstet Gynecol 1962;84:930-5.

29. Friedman EA, Niswander KR, Bayonet-Rivera NP, Sachtleben MR. Prelabor status evaluation II. Weighted score. Obstet Gynecol 1967;29:539-44.

30. Watson WJ, Stevens D, Welter S, Day D. Factors predicting successful labor induction. Obstet Gynecol 1996;88:990-2.

31. Satin AJ, Leveno KJ, Sherman ML, McIntire DD. Factors affecting the dose responseto oxytocin for labor stimulation. Am J Obstet Gynecol 1992;166:1260-1.

32. Chandra S, Crane JM, Hutchens D, Young DC. Transvaginal ultrasound and digital examination in predicting successful labor induction. Obstet Gynecol 2001;98:2-6.

33. Crane JM, Delaney T, Butt KD, Benett KA, Hutchens D, Young DC. Predictors of successful labor induction with oral or vaginal misoprostol. J Matern Fetal Neonat Med 2004;15:319-23.

34. Ramsey PS, Ogburn PL Jr, Harris DY, Heise RH, Ramin KD. Effect of vaginal pH on efficacy of the dinoprostone gel for cervical ripening/labor induction. Am J Obstet Gynecol 2002;187:843-6. 
Influential factors on cervical ripening by prostaglandin E2

35. Ramsey PS, Ogburn PL Jr, Harris DY, Heise RH, DiMarco CS, Ramin KD. Effect of vaginal ph on efficacy of the dinoprostone vaginal insert for cervical ripening/ labor induction. J Matern Fetal Neonatal Med 2003;13:250-3. 